\title{
Kampf dem Vorurteil
}

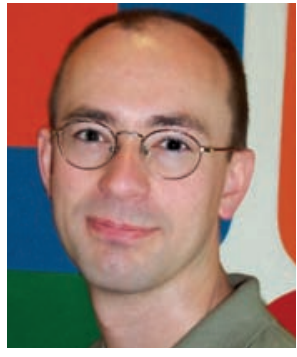

Dr. med. Dieter Schmid, Redaktionsleitung
— Kennen Sie den? Der Internist hat Ahnung, kann aber nichts. Der Chirurg hat keine Ahnung, kann aber alles. Der Pathologe weiß alles, kann alles, kommt aber immer zu spät. Lustig? Ja, schon. Das Problem mit solchen Stereotypen ist nur, dass sie im Alltag zu unangenehmen Spannungen führen. Mediziner sind ja so weltoffen und tolerant! Wenn es aber um Kollegen anderer Fächer geht, treten mitunter seltsame Vorbehalte zutage. Ein PJ-Student erzählte mir vor kurzem folgende Geschichte: Zusammen mit seinem Oberarzt stand er bei der letzten OP des Tages mit am Tisch. Alle waren prima gelaunt. Der Chirurg erklärte viel und gab Anekdoten zum Besten. Irgendwann stellte er dann die Frage: „Und, was möchten Sie später mal werden?“ Der Student antwortete wahrheitsgemäß: „Och, eigentlich könnte ich mir Innere ganz gut vorstellen ... "Danach habe Stille im Raum geherrscht. Betretenes Schweigen. Und im restlichen Tertial habe ihm der Oberarzt bei einer OP nie wieder etwas erklärt. Ist das nicht noch lächerlicher als der obenstehende Witz? Schließlich leisten alle Mediziner Herausragendes - egal in welchem Fach. In dieser Via medici stellen wir Ihnen zwei Fächer vor, die von ihren Medizinerkollegen besonders gerne geschmäht werden: Anästhesisten werden von ihren direkten Kollegen - den Chirurgen - gerne als „Schlafwagenschaffner“ verhöhnt. Plastische Chirurgen wiederum werden von den Operateuren anderer Fächer als „Skalpell-Kosmetiker“ belächelt. Unsere Artikel „Zwischen Panik und Picknick“

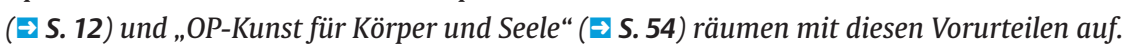

- Wohin Stereotype führen, wenn sie sich ungehemmt entfalten können, beschreibt Susanne Krasz aus Dresden in ihrem Artikel „Vernarbte Fronten“. Sie hat mit dem „famulieren E engagieren“-Programm der IPPNW in Bosnien famuliert. In diesem Land haben sich vor 15 Jahren Menschen gegenseitig massakriert, weil ihnen plötzlich Nationalitäten und Religionszugehörigkeiten wichtiger waren als die Tatsache, dass sie zuvor Jahrhunderte friedlich zusammengelebt haben. Erschrocken stellte unsere Autorin fest, wie sehr dieser Krieg die Menschen bis heute prägt. Sie sah viele Patienten mit vernarbten Kriegswunden. Schlimmer noch empfand sie allerdings die Wunden in den Köpfen und den Hass, der bis heute weiterlebt $(\rightarrow S .32)$.

- Positiv für das Arztleben prägen soll Medizinstudenten das Praktische Jahr. Leider ist häufig das Gegenteil der Fall: Die Auswertung unserer PJ-Umfrage 2007 zeigt, wie demotivierend viele diesen Ausbildungsabschnitt empfinden $(\rightarrow$ S. 20). Via medici führt diese Umfrage seit 2003 regelmäßig durch. Dieses Jahr legten wir besonderen Wert auf die Frage, ob sich die neue AO mittlerweile positiv niederschlägt. Das Ergebnis ist wenig schmeichelhaft für die neue Studienordnung. Nur 32 Prozent der Studenten, die nach neuer AO studiert haben, sehen sich - was theoretische Kenntnisse anbelangt - gut auf das PJ vorbereitet. Bei den Studenten, die noch nach der alten $A O$ studiert haben, sind das immerhin 68 Prozent! Die wichtigste Ursache für dieses Problem: Den Studenten fehlt das Wissen, das sie sich früher in der Vorbereitung auf das alte 2. Staatsexamen erarbeitet haben. Kein Wunder also, dass 94 Prozent (!) aller PJler fordern, dass der theoretische Teil der 2. Ärztlichen Prüfung wieder vor dem PJ stattfinden muss. Mehr zu diesem Thema und über die Chancen, dass dieser Wunsch Wirklichkeit wird, unter www.thieme.de/viamedici/downloads/podcasts/uebersicht.html.

In diesem Sinne: Seien Sie tolerant - aber lassen Sie sich nicht alles gefallen! Vorweihnachtlich grüßt Sie

Ihr

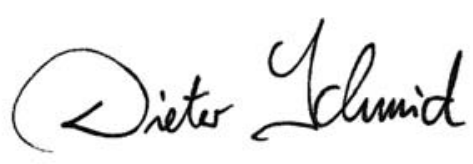

\section{„Mann, jetzt sei doch nicht so empfindlich, nur weil er einmal zu dir ,Beuteldrücker anstatt ,Sandmännchen' sagt ..."}

